\title{
USING PROLIFERATION-RESISTANT FUELS TO MANAGE GLOBAL PLUTONIUM INVENTORIES: GOING WELL BEYOND THE SPENT-FUEL STANDARD
}

\author{
Paul Chodak III \\ Los Alamos National Laboratory \\ P.O. Box 1663, MS K551 \\ Los Alamos NM 87545 \\ (505) 665-1579
}

\section{ABSTRACT}

The National Academy of Sciences has stated that the growing global stocks of civil and weapons plutonium represent a "clear and present danger." Proliferation-resistant fuels (PRFs) have been proposed by researchers in several countries including France, Italy, Switzerland, Japan and the United States (US) as an effective sink for this plutonium. In place of the $\mathrm{UO}_{2}$ in mixed uranium-plutonium dioxide (MOX), PRFs blend a nonfertile-oxide-diluant and burnable poisons with $\mathrm{PuO}_{2}$. The resultant ceramic is more chemically durable than MOX; consequently, the plutonium cannot be recovered by standard Plutonium-Uranium Reduction Extraction (PUREX) processing and is a more durable waste form than MOX. In the absence of the in situ production of ${ }^{239} \mathrm{Pu}$ or ${ }^{233} \mathrm{U}$ found in MOX and thorium fuels, respectively, an extremely deep burn of the plutonium is possible, producing a spent fuel that goes well beyond the spent-fuel standard. Calculations have shown that the reactivity behavior of these fuels can be tailored through the appropriate incorporation of burnable poisons to enable their use in existing lightwater reactors without hardware or operational modifications. Depending on the fuel management strategy employed, PRFs destroy $60-80 \mathrm{wt} \%$ of their total plutonium charge, more than twice the consumption possible with MOX fuel. In addition, the isotopics of the residual spent plutonium are $>50 \mathrm{wt} \%$ ${ }^{242} \mathrm{Pu},<20 \mathrm{wt} \%$ fissile plutonium, and $>3 \mathrm{wt} \%{ }^{238} \mathrm{Pu}$ as compared with $<15 \mathrm{wt} \%{ }^{242} \mathrm{Pu},>70 \mathrm{wt} \%$ fissile plutonium, and $<1 \mathrm{wt} \%{ }^{238} \mathrm{Pu}$ for spent MOX. Spent PRF is, therefore, a substantially less attractive source for weapons material than spent MOX. A once-through, one-third PRF core consumes $90 \mathrm{~kg}$ of plutonium, whereas a one-third MOX core produces $70 \mathrm{~kg}$. Thus, PRFs can be used to reduce plutonium inventories and the overall proliferation risk posed by commercial fuel cycles. It is recommended that the US Department of Energy develop PRFs on a not-to-interfere basis with the ongoing Material Disposition MOX program. Development of PRFs as a follow on to MOX for burning excess weapons plutonium could be leveraged to promote PRF consumption of global separated civil- plutonium stocks. Thus, the US could take an active leadership role to enhance the proliferation resistance of commercial nuclear fuel cycles.

\section{INTRODUCTION}

Current light-water-reactor (LWRs) fuel cycles were originally envisioned to include continuos reprocessing of spent fuel and the eventual use of fastreactor technology to close the fuel cycle. However, several factors, including larger-than-expected globaluranium reserves, slower-than-projected growth in energy demand, and diminished public acceptance of nuclear power at a minimum, postpone and potentially permanently prevent the deployment of fast-spectrum, advanced reactors and closing of the fuel cycle. Consequently, global plutonium inventories grow in the absence of an effective plutonium sink in LWR fuel cycles. Cumulative civilian reactor discharges are projected to reach $\sim 1400$ metric tons (MT) of plutonium by the year 2000 and then continue to grow by 75 MT annually. ${ }^{1}$ Of the 1400 MT, $\sim 1100$ will remain in spent fuel with separated reactor-grade plutonium stores growing to $150-200$ MT by the year 2000. In addition, 100 MT of United States (US) and Russian weapons plutonium (WPu) has been declared excess and is earmarked for disposition. There is also the potential that more $\mathrm{WPu}$ will be declared excess as a result of continuing arms reduction efforts. ${ }^{2}$

In recognition of the proliferation risks associated with both military and civilian plutonium, the National Academy of Sciences (NAS) stated in their 1994 report on excess WPu disposition that "Further steps should be contemplated, however, to move beyond the spent-fuel standard and reduce the security risk posed by all the world's plutonium stocks, military and civilian, separated and unseparated; the need for such a step already exists and will increase with time."” In addition to the real proliferation risks, large stores of civil plutonium in nonweapons states with advanced technology, such as Japan, may be perceived by their neighbors as having a virtual or latent weapons capability, thereby fueling regional tensions. Furthermore, unabated growth in global plutonium 
inventories provides nuclear-power critics with ammunition in their efforts to shut down or phase out nuclear power.

Whereas advanced fast-spectrum nuclear systems could theoretically both solve waste problems and provide long-term sustainable sources of environmentally benign power, they are not projected to be deployed in any significant numbers for another four or five decades. It is generally accepted that uranium supplies are sufficient to support current once-through LWR cycles for three to five decades, depending on the nuclear-energy demand growth scenario. ${ }^{4}$ Until a reduction in available uranium reserves makes fastspectrum systems and reprocessing economically viable, it is not likely that significant numbers of advanced, plutonium-consuming, nuclear systems will be deployed. Thus, by default, LWRs will continue to be the only vehicles available to transmute significant quantities of plutonium well into the next century. There remains a near-term problem of reducing the riskexisting plutonium inventories. These inventories will continue to grow as a byproduct of current LWR cycles. The risk posed by existing stocks, particularly that posed by separated plutonium stocks, must be mitigated to acceptable levels regardless of the future of nuclear power. Nuclear power phaseout and large-scale growth scenarios are possible. This uncertainty suggests the need for a flexible solution that can use existing LWRs to transition to a wide range of potential, future, fuelcycle plutonium requirements. Significant and permanent reduction of the risk posed by these stocks requires burning of this excess plutonium, civilian and military, well beyond the spent-fuel standard.

This paper proposes the use of non-uranium fuels, here termed proliferation resistant fuels (PRFs), as a sink for excess military and civil plutonium. These fuels can be qualified and deployed in the near term, $\sim 10$ years or less, to consume plutonium beyond the spent-fuel standard in existing LWRs. A brief review is presented of some of the work done to date establishing the feasibility of burning PRFs in LWRs. Next, the efficacy and proliferation-resistance aspects of plutonium burning in mixed uranium-plutonium dioxide (MOX), compared with that of PRFs, is presented. Finally, using PRFs as a follow on to using MOX to burn US WPu is proposed as a means of advancing PRFs in the commercial fuel cycle.

\section{FEASIBILITY OF BURNING PRFs IN LWRs}

PRFs have been proposed by researchers in several countries including France, Italy, Switzerland, Japan and the United States (US) as an effective sink for plutonium. PRFs are designed to behave like standard, low-enriched uranium fuel, enabling them to be used in standard LWR fuel cycles without reactor modification. Because PRFs contain no uranium, burnable poisons are used to tailor neutronic properties. The inert matrix material is a neutronically inert diluant and provides the required thermophysical properties of the fuel. The theoretical feasibility of burning PRFs in LWRs has been confirmed through fuel-cycle calculations and material-property characterizations.

The reactivity swing and coefficients produced by the alternate incorporation of boron, holmium, dysprosium, erbium, hafnium, samarium, and europium has been studied. ${ }^{5}$ Doppler, moderator temperature, and void coefficients tends to be somewhat less negative than uranium-containing fuels. Control absorber worths are also somewhat reduced because of the greater crosssection of plutonium. However, the core-average reactivity parameters of a heterogeneous core, composed of $30-40 \%$ uniformly distributed PRF assemblies (the remainder are $\mathrm{UO}_{2}$ assemblies), are well within existing LWR safety envelopes. Pin-to-pin power peaking can be controlled through the zoning of burnable poisons and PRF enrichment. Similar results reported by the Japan Atomic Energy Research Institute and others also confirmed the feasibility of these fuels' partial LWR cores. ${ }^{6,7}$ Lombardi and Mazzola examined heterogeneous assemblies with $20-30 \%$ PRF rods uniformly distributed in $\mathrm{UO}_{2}$ assemblies. ${ }^{8,9}$ Ebia's $0.3 \mathrm{eV}$ resonance peak was found to be helpful in providing temperature feedback; gadolinia provided beginning-of-cycle excess reactivity control while minimizing end-of-cycle reactivity penalties. US weapons-grade plutonium disposition studies found PRFs to be a promising option. ${ }^{10,11}$ An exceptionally deep burn, consuming $80 \%$ total plutonium with the isotopics of the residual $20 \mathrm{wt} \%$ containing $>70 \mathrm{wt} \%$

${ }^{242} \mathrm{Pu}$, was reported for a cycle wherein the periphery of the core was loaded with PRF assemblies. ${ }^{12,13}$ Concerns about local transient behavior within PRF fuel zones are expected to be manageable but must be resolved. The common conclusion that can be drawn from these reports is that PRFs appear both feasible from a physics and reactor safety standpoint and desirable as an alternative to MOX for plutonium burning.

Several years of research have culminated in the identification of three promising candidate PRF inert matrices: cubic stabilized zirconia $\left(\mathrm{ZrO}_{2}\right)$, silicon carbide (SiC) coated $\mathrm{PuO}_{2}$ kernel particle fuel, and a ceramic-ceramic two-phase fuel with $\mathrm{ZrO}_{2}$ islands in a 
spinel matrix. ${ }^{14}$ Researchers at Paul Scherrer Institute, Los Alamos National Laboratory, and the Japan Atomic Energy Research Institute have fabricated cubicstabilized zirconia fuel doped with erbia $\left(\mathrm{ZrO}_{2}-\mathrm{PuO}_{2}-\right.$ $\mathrm{Er}_{2} \mathrm{O}_{3}$ ) and found that it is a solid solution, fluorite structure that is highly radiation resistant and extremely durable as a waste form. ${ }^{15-18}$ The low-thermal conductivity of $\mathrm{ZrO}_{2}$ can be accommodated through the use of annular fuel, which reduces centerline temperatures to within standard LWR envelopes. SiC coated particle fuel with $\mathrm{PuO}_{2}$ and $\mathrm{Er}_{2} \mathrm{O}_{3}$ kernels bound in graphite compacts as well as solid solution islands of $\mathrm{ZrO}_{2}-\mathrm{PuO}_{2}-\mathrm{Er}_{2} \mathrm{O}_{3}$ islands in a spinel ceramic phase have much higher thermal conductivity than $\mathrm{UO}_{2}$; however, less is known concerning their radiation resistance.

The results of extensive theoretical studies are extremely promising. However, deployment of PRFs will require a significant fuel development and qualification program. More work remains to be done in the development of transition fuel-management core designs as well as transient-design-basis physics analysis. In addition, more verification of anticipated fuel thermophysical behavior is required. Initial irradiation experiments of these ceramic fuels in the Halden Reactor are planned to start in 1999.

\section{EFFICACY AND PROLIFERATION ASPECTS OF PLUTONIUM BURNING IN MOX VS PRF}

\section{A. Greater Plutonium Destruction Potential}

MOX fuels are already used to burn plutonium in the LWRs of several nations. Unfortunately, some neutrons are produced when MOX fuel plutonium fissions are captured in MOX's ${ }^{238} \mathrm{U}$, which breeds more ${ }^{239} \mathrm{Pu}$. This in situ production of fissile material substantially reduces the maximum net plutonium destruction possible in MOX. Similarly, neutron capture in ${ }^{232} \mathrm{Th}$ breeds fissile ${ }^{233} \mathrm{U}$ and thus reduces, although to a somewhat lesser degree, plutonium destruction achievable through the use of thorium fuels. PRFs encapsulate plutonium and burnable poisons in a nonuranium matrix. Because they do not contain uranium or thorium, PRFs do not produce plutonium or uranium. Consequently, PRFs can destroy more of their plutonium charge than MOX over identical reactor cycles. Both one-third MOX and one-third PRF LWR cores produce plutonium in the two-thirds of the core loaded with $\mathrm{UO}_{2}$. However, the one-third PRF core yields a net consumption of $90 \mathrm{~kg}$ of plutonium, whereas a one-third MOX core produces $70 \mathrm{~kg}$, as shown in Fig. 1.
This is because the one-third of the core loaded with MOX fuel consumes only $30 \%$ of its original plutonium content, whereas PRF fuel consumes as much as $80 \%$, as shown in Fig. 1. In addition, the isotopics of the residual spent plutonium are $>50 \mathrm{wt} \%$ ${ }^{242} \mathrm{Pu},<20$ wt $\%$ fissile plutonium, and $>3 \mathrm{wt} \%{ }^{238} \mathrm{Pu}$, as compared with $<15 \mathrm{wt} \%{ }^{242} \mathrm{Pu},>70 \mathrm{wt} \%$ fissile plutonium, and $<1 \mathrm{wt} \%{ }^{238} \mathrm{Pu}$ for spent $\mathrm{MOX}$, as shown in Fig. 2. Unlike spent MOX, spent PRF plutonium is burned well beyond the spent-fuel standard. By varying cycle and PRF parameters, a full spectrum of global plutonium inventory management strategies ranging from sharp reductions to controlled growth, including maintenance of an equilibrium inventory, could be achieved.

\section{B. Enhanced Inherent Proliferation Barriers}

Table 1 lists some commonly considered spentfuel plutonium characteristics related to the utility of the material for weapons use. The ratio of the values listed are calculated based on the above spent-fuel plutonium isotopics for once-through spent MOX and PRF fuels resultant from identical three 292 day/cycles (3 years with 0.8 Capacity Factor) at a power density of 17.7 MW/assembly. The spent PRF neutron emission rate is greater by a factor of 4.8 over that of MOX. The decay heat is nearly six times higher in spent PRF. The critical mass of spent PRF plutonium is 3.2 times as great as spent MOX plutonium and contains one-fourth the fissile plutonium per unit mass. Also, the total plutonium density is reduced in spent PRF relative to the spent MOX. Consequently, more spent PRF would have to be processed to recover the same amount of plutonium than could be recovered from spent MOX. In addition, none of the proposed PRF inert matrices can be processed by conventional PUREX reprocessing. It is likely that the PRF matrices would require more sophisticated processing to recover the plutonium, thus requiring a process development effort that would have to be fine-tuned once the spent fuel had been acquired. In short, it would take longer to fabricate a weapon from spent PRF, the weapon design would be more complex, and its performance would be much less reliable. 
Fig. 1. Comparison of MOX and PRF Net Plutonium Destruction Per 1/3-Core and Residual Weight Percent Plutonium in Spent Fuel

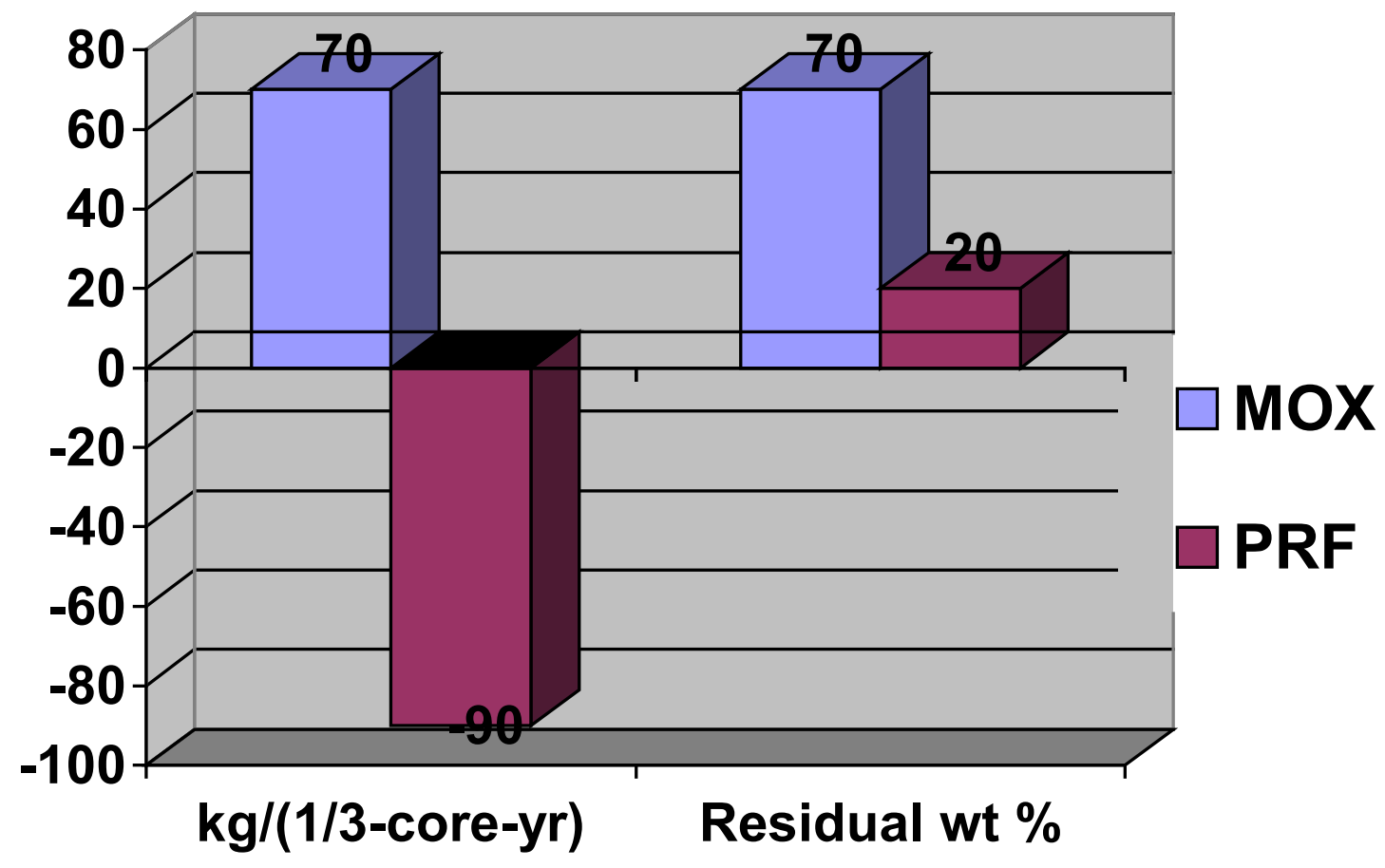

Fig. 2. Comparison of MOX and PRF Spent-fuel Plutonium Residual Isotopics

\section{Spent MOX}

\section{Spent PRF}
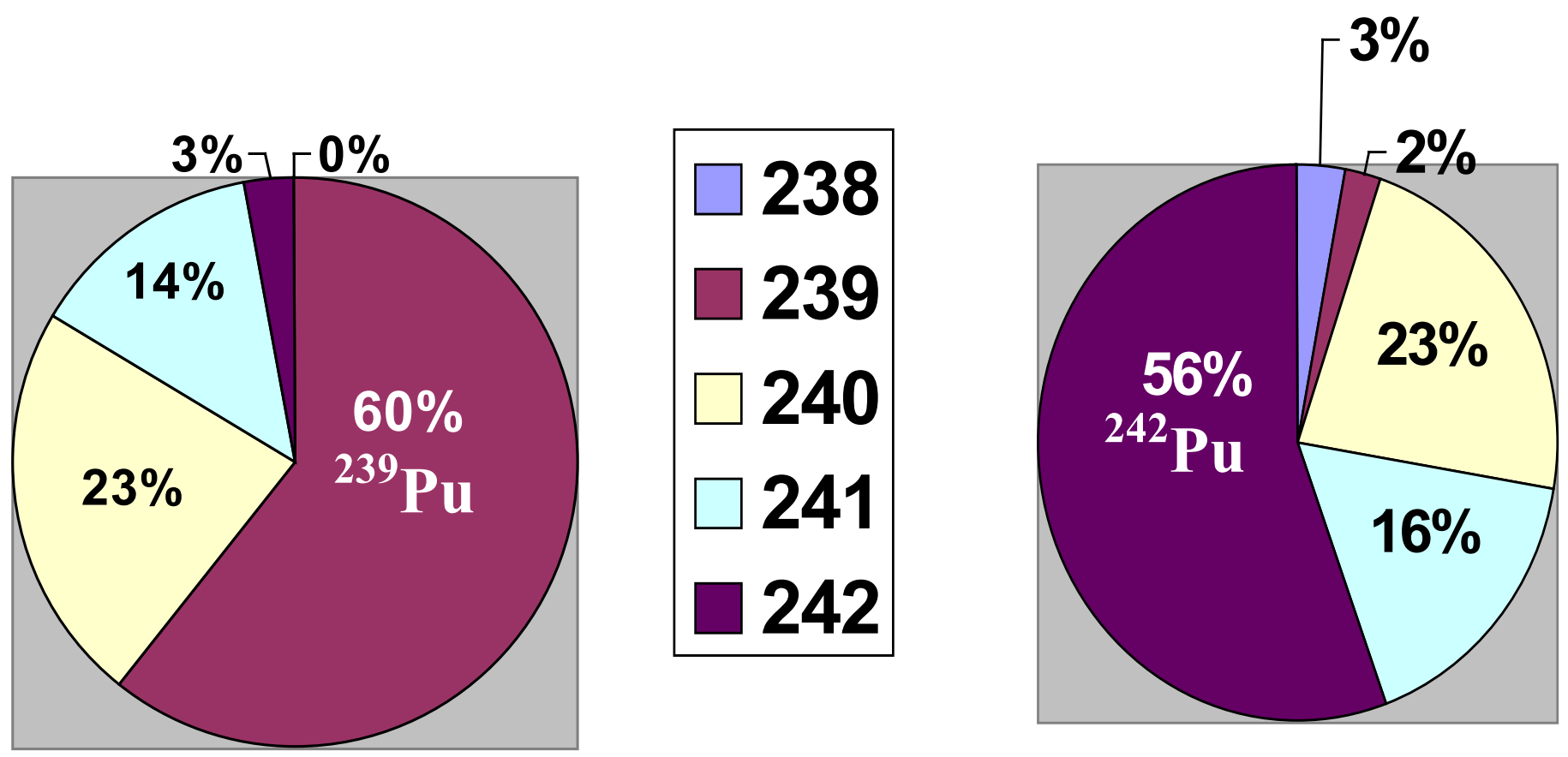


\begin{tabular}{|l|c|c|}
\hline \multicolumn{2}{|c|}{ Table 1. Weapons Utility of Recovered Plutonium } \\
\hline \multicolumn{1}{|c|}{ Barrier } & Units/Scale & $\begin{array}{c}\text { Ratio of MOX/PRF } \\
\text { Values }\end{array}$ \\
\hline $\mathrm{Pu}$ Isotopics & gms fissile/100 gm Pu & 0.25 \\
\hline Critical Mass & $\mathrm{kg} \mathrm{Pu}$ & 3.2 \\
\hline Neutron Emission & $\mathrm{n} / \mathrm{s} \mathrm{kg} \mathrm{Pu}$ & 4.8 \\
\hline Decay Heat & $\mathrm{kW} / \mathrm{ton} \mathrm{Pu}$ & 5.9 \\
\hline
\end{tabular}

\section{More Durable Waste Form}

PRFs can also be used to reduce long-term repository risk. Actinides and long-lived fission products (LLFPs) are the primary sources of geologic repository health risks. PRFs contain no uranium, which significantly reduces the production of actinides. Although a smaller advantage, LLFPs can be incorporated into fresh PRF and burned in LWRs. Although the ability to burn LLFPs in LWRs is very limited, the same chemical durability that makes the PRFs more difficult to reprocess than MOX also reduces their nuclide release rates, thus further reducing overall repository risk.

\section{PRF vs MOX Summary}

Burning plutonium in PRFs will enhance the proliferation resistance of the commercial fuel cycle by enabling a real draw down in global plutonium inventories with one-third core LWR cycles. Spent PRF is extremely less attractive than spent MOX as a source for weapons plutonium. Furthermore, although it is theoretically possible to make a nuclear explosive with the plutonium found in spent PRF, it is not likely that spent PRF would ever be a preferred source for weapons materials even after the radiation barrier decayed away.

\section{USE OF PRFs TO BURN WPU}

The 100 MT of WPu declared surplus by the US and Russia comprise $<10 \%$ of the world's plutonium inventory. The remaining $>90 \%$ of the global plutonium inventory is in the civilian fuel cycle. About $80 \%$ of this is in spent fuel and is at the spent-fuel standard. In its report on $\mathrm{WPu}$ disposition options, the NAS recognized the potential and desirability of advanced fuels for burning $\mathrm{WPu}$ well beyond the spent-fuel standard. However, the immediacy of the risk posed by separated excess WPu led the NAS to reject the use of advanced fuels because the delay required to develop and deploy these fuels was unjustified because the vast majority of all the world plutonium is at the spent-fuel standard. However, it bears repeating that in so deciding, the NAS also concluded that "Further steps should be contemplated, however, to move beyond the spent-fuel standard and reduce the security risk posed by all the world's plutonium stocks, military and civilian, separated and unseparated; the need for such a step already exists and will increase with time." 3

In making their decision, the NAS envisioned a rapid response, accelerated $\mathrm{WPu}$ disposition program. Today's WPu MOX program is not scheduled to begin production-level irradiation of WPu MOX until 2007 and is to be completed by 2017. Even if it took 10 years to qualify PRFs and establish some fabrication capacity (potentially less than the design throughput of the WPu MOX plant might be established initially), 7 of the scheduled 10 years of the MOX irradiation period would remain. In addition, given both the contentious nature of this program domestically and the requirement for a parallel Russian program, there is a substantial potential for delay in the MOX irradiation schedule. Even further, on-going disarmament talks may prove successful and may result in the US and Russia declaring more of their WPu inventories excess.

The disposition of US WPu using MOX fuel is an ongoing program whose momentum should not be interrupted. However, PRFs should be considered as a next-generation fuel form for concurrent development. When viewed within the context of the larger risk posed by commercial plutonium, using the WPu MOX program to leverage the development of PRFs becomes quite clear. An active PRF program would open the door for positive international cooperation, enabling the US to lead efforts to enhance the proliferation resistance of commercial nuclear fuel cycles. 


\section{SUMMARY}

The NAS has stated that the growing global stocks of civil and weapons plutonium represent a "clear and present danger." It is unlikely that fastspectrum burners will be available for at least four or more decades, which leaves LWRs as the only means available to address this problem in the interim. PRFs provide a means for reducing global stores of plutonium in a once-through, one-third LWR core cycle using existing reactors. Spent PRF is extremely less attractive than spent MOX as a source for weapons plutonium. Furthermore, although it is theoretically possible to make a nuclear explosive with the plutonium found in spent PRF, it is unlikely that spent PRF would ever be a preferred source for weapons materials even after the radiation barrier decayed away. The theoretical feasibility of burning plutonium in existing LWRs with PRFs has been well established from a physics and materials viewpoint. A significant, potential 5- to 10year development program is required before PRFs can be deployed.

The disposition of US WPu using MOX fuel is an ongoing program whose momentum should not be interrupted. However, PRFs should be considered as a next-generation fuel form for concurrent development. When viewed within the context of the larger risk posed by commercial plutonium, using the WPu MOX program to leverage the development of PRFs becomes quite clear. An active PRF program would open the door for positive international cooperation enabling the US to lead efforts to enhance the proliferation resistance of commercial nuclear-fuel cycles.

\section{REFERENCES}

1. D. Albright,, F. Berkhout, and W. Walker, Plutonium and Highly Enriched Uranium 1996: World Inventories, Capabilities and Policies, Oxford University Press (1997).

2. M. Reiss, Bridled Ambition; Why Countries Constrain Their Nuclear Capabilities (Johns Hopkins University Press, Washington, DC, 1995).

3. "Management and Disposition of Excess Weapons Plutonium," National Academy of Sciences, Committee on International Security and Arms Control (1994).

4. R. A. Krakowski, C. G. Batheke, and P. Chodak. "Reduction of Worldwide Plutonium Inventories Using Conventional Reactors and
Advanced Fuels: A Systems Study," International Conference on Future Nuclear Systems: Challenges Towards Second Nuclear Era with Advanced Fuel Cycles (Global '97), Yokahama, Japan, October 5-10, 1997.

5. J. M. Paratte and R. Chawla, "On the Physics and Feasibility of Light Water Reactor Plutonium Fuels Without Uranium," Annals of Nuclear Energy 7 (July 1995).

6. H. Akie, T. Muromura, H. Takano, and S. Matsuura, "A New Fuel Material for OnceThrough Weapons Plutonium Burning," Nuclear Technology 107(2), 182-191 (1994).

7. P. Chodak and J. J. Buksa, "A Practical Strategy for Reducing the Future Security Risk of United States Spent Nuclear Fuel," International Conference on Future Nuclear Systems: Challenges Towards Second Nuclear Era with Advanced Fuel Cycles," (GLOBAL '97) Yokahama, Japan, October 5-10, 1997.

8. C. Lombardi and A. Mazzola, "Plutonium Burning in Pressurized Water Reactors Via NonFertile Matrices," Nuclear Science and Engineering 122, 229-239 (1996).

9. C. Lombardi and A. Mazzola, "Exploiting The Plutonium Stockpiles in PWRs by Using Inert Matrix Fuel," Annals of Nuclear Energy 23 (14), 1117-1126 (1996).

10. J. W. Sterbenz, C. S. Olsen, and U. P. Sinha, "Weapons Grade Plutonium Disposition, Volume 4: Plutonium Dispositioning in Light Water Reactors," DOE/ID-10422, pp. 14-15 (June 1993).

11. G. S. Chang, "Physics Analysis of Tungsten in Weapons-Grade U/Pu Fuels for LWR U/Pu Burning/Power Reactors," Trans. Am. Nucl. Soc. 70, 90-91 (June 1994).

12. P. Chodak, M.J. Driscoll, M.M. Miller, and N.E. Todreas, "Destruction of Plutonium Using NonUranium Fuels in Pressurized Water Reactor Peripheral Assemblies," Massachusetts Institute of Technology report MIT-NFC-TR-001 (1997).

13. P. Chodak, M. J. Driscoll, and N. E. Todreas, "A Pressurized Water Reactor Deep Burn Plutonium Fuel Cycle," paper presented at Fourth International Conference on Nuclear 
LA-UR-99-2860

Engineering, New Orleans, Louisiana (March 1996).

14. Inert Matrix Working Group Conference, Paul Scherrer Institute, Villigen, Switzerland, October 13-17, 1998.

15. C. Degueldre, U. Kasemeyer, F. Botta, and G. Ledergerber, Mater. Res. Soc. Symp. Proc. 412 15-24 (1996).

16. C. Degueldre, U. Kasemeyer, and F. Botta, "Study of Plutonium Incineration in LWRs Employing a Uranium Free Fuel Inert MatrixBurnable Poison-Actinide Approach," Paul Scherrer Institute report TM-43-95-12 (May 1995).

17. K. E. Sickafus, Hj. Matzke, T. Hartmann, K. Yasuda, J. A. Valdez, P. Chodak III, M. Nastasi, and R. Verrall, "Radiation Damage Effects in Zirconia," Inert Matrix Working Group Conference, Villigen, Switzerland, October 13-17, 1998.

18. S. Eaton, et. al., "Development of Nonfertile and Evolutionary Mixed Oxide Nuclear Fuels for Use in Existing Water Reactors," Los Alamos National Laboratory document LA-UR-97-1359 (1997). 